\title{
Palliative Care Symposium: Promoting Joint Palliative Care
}

\author{
Held on 28 March 2011 at the Royal College of Physicians of Edinburgh
}

\author{
K Henriksen \\ Specialist Registrar in Palliative Care, Marie Curie Hospice, Edinburgh, UK
}

Correspondence to $K$ Henriksen,

Marie Curie Hospice,

Frogston Road West,

Edinburgh, EHIO 7DR, UK

DECLARATION OF INTERESTS No conflict of interests declared.

$$
\begin{aligned}
& \text { tel. }+44(0) \text { I3I } 470220 \text { I } \\
& \text { e-mail } \\
& \text { p.henriksen@blueyonder.co.uk }
\end{aligned}
$$

This symposium addressed a number of common, yet often more complex aspects of both general and specialist practice.

\section{SESSION I: INTEGRATION OF PHYSICAL AND NON-PHYSICAL SYMPTOMS}

Dr Lesley Colvin (Senior Lecturer in Anaesthesia,Western General Hospital, Edinburgh) discussed the challenges of pain management in patients with a history of addiction. Similar to other chronic conditions, substance misuse often follows a relapsing course. Pain is a frequently associated comorbidity. Mortality rates are high but can be reduced by successful methadone maintenance programmes, although pain, anxiety and depression have a negative effect on outcomes. Dr Colvin described experience of the Lothian Pain and Dependency Clinic. General guidance on patient management is available through the British Pain Society Guidelines.'

By screening outpatients attending a regional cancer centre, Professor Michael Sharpe (Professor of Psychological Medicine, Universities of Edinburgh and Oxford) demonstrated that current services are poor at identifying and treating depression in cancer patients. ${ }^{2}$ Failure to manage depression may have a detrimental effect on quality of life, treatment adherence and survival, however, screening for and treating depression can provide greater benefits than some anti-cancer treatments in terms of quality adjusted life years. ${ }^{3}$ Fatigue and pain also cluster with distress and active disease, suggesting cancer treatment and symptom relief programmes should run in parallel to avoid prolonging life at the expense of quality.

\section{SESSION 2: INFLAMMATION AND CANCER SYMPTOMS}

Dr Neil MacDonald (Oncologist and Palliative Care Physician, Cancer Nutrition-Rehabilitation Programme, Montreal, Canada) reviewed the role of inflammation in cancer and related symptoms. We were reminded that C-reactive protein (CRP) identifies cancer patients with a poorer prognosis and asked if this cheap test could be used to better direct oncological treatment. Raised CRP also correlates with higher rates of pain, fatigue and cachexia, and there is now evidence that early palliative care not only generates better quality of life scores, but can also prolong survival. ${ }^{4}$ A survival benefit from nonsteroidal anti-inflammatory drug (NSAID) use in advanced cancer has also been suggested, ${ }^{5}$ supporting the rationale for prioritising research around antiinflammatory therapies.

Systemic inflammation was described by Professor Kenneth Fearon (Professor of Surgical Oncology and Honorary Consultant Colorectal Surgeon, Western General Hospital, Edinburgh) as one of the key features of cancer cachexia, together with muscle loss and reduced food intake. The recently published international consensus statement on cancer cachexia ${ }^{6}$ defines this multifactorial syndrome as a spectrum from early changes (pre-cachexia) to severe incapacity (refractory cachexia). Four key assessment domains were outlined; food intake, catabolic drivers, muscle mass and physical functioning, recognising accurate assessment is challenging in the sarcopenic elderly and the obese. Multimodal cachexia treatment has been shown to improve quality of life if targeted to patients at earlier stages of the spectrum.

\section{SESSION 3: NON-MALIGNANT DISEASE}

Dr Miriam Johnson (Senior Lecturer in Palliative Medicine and Honorary Consultant Physician, Hull York Medical School,) reviewed the evidence for the mechanisms and management of chronic breathlessness. Following optimisation of underlying conditions and treatment of reversible factors, there are a number of strategies that can be implemented: exercise to prevent deconditioning, pacing and prioritising tasks, setting realistic goals, breathing training and provision of appropriate aids. Opioids can make small but perceptible improvements and may have a role as part of the total care package. Similar studies for benzodiazepines are lacking but these can be particularly useful where anxiety and panic predominate. The evidence that oxygen improves the sensation of chronic breathlessness 
is limited. A cheaper, safer and proven alternative is the handheld fan. ${ }^{7}$

Professor Irene Tracey (Director of the Oxford Centre for Functional Magnetic Resonance Imaging of the Brain) presented results using methods such as functional magnetic resonance imaging (MRI), positron emission tomography, magnetoencephalography and pharmacological functional MRI. Objective readouts can be produced for subjective pain experiences, highlighting the neuroanatomy involved and demonstrating the complex, bilateral cortical activation that provides extra layering to the pain experience. We may now have the potential to interpret an individual's pain signature map and see how this has evolved from a number of different pain processes. We also have a means of illustrating the effects of analgesics on the human brain, and the mechanism of the placebo response, ${ }^{8}$ pertinent to the management of patients across the diagnostic spectrum and for future drug development.

\section{SESSION 4: PAEDIATRIC PALLIATIVE CARE}

Dr Richard Hain (Senior Lecturer and Honorary Consultant in Paediatric Palliative Medicine, University of Cardiff) introduced the final session by outlining the major differences between UK adult and paediatric palliative care services. He was followed by two case presentations from Dr Fariel Rahman (SpR in Neurodisability, Royal Hospital for Sick Children, Glasgow) and Dr Diana Mclntosh (SpR in Oncology, Royal Hospital for Sick Children, Glasgow) describing circumstances where information had been withheld from children suffering from life-limiting conditions by their parents, and by others at the parents' request. Dr Hain asked the audience to consider the ethical basis for such actions and how we might develop an appropriate approach to children in such circumstances.

\section{TAKE-HOME MESSAGE}

This excellent symposium considered the remit and possibility of effective palliative care in general and specialist practice. We are learning more about caring for patients with conditions other than cancer. We are also appreciating that a palliative approach can positively impact not only on quality of life but also longevity. In an era of financial constraint, but with an obligation to provide high quality care for all, investment needs to be carefully considered and resources utilised in line with potential benefit. It is reassuring to acknowledge that with palliative care, we can deliver.

\section{REFERENCES}

I The British Pain Society. Pain and substance misuse: Improving the patient experience. London: The British Pain Society; 2007. Available from: http://www.britishpainsociety.org/book_drug_misuse_main.pdf

2 Sharpe M, Strong V, Allen K et al. Major depression in outpatients attending a regional cancer centre: screening and unmet treatment needs. Br J Cancer 2004; 90:3 I4-20. doi:I0.1038/sj.bjc.660I578

3 Strong V, Waters R, Hibberd C et al. Management of depression for people with cancer (SMaRT oncology I): a randomised trial. Lancet 2008; 372:40-48. doi:I0.10I6/S0I40-6736(08)6099I-5

4 Temel J, Greer J, Muzikansky A et al. Early palliative care for patients with metastatic non-small-cell lung cancer. N Engl J Med 2010; 363:733-42. doi:10.1056/NEJMoa I000678

5 Lundholm K, Gelin J, Hyltander A et al. Anti-inflammatory treatment may prolong survival in undernourished patients with metastatic solid tumours. Cancer Res 1994; 54:5602-06.

6 Fearon K, Strasser F,Anker SD et al. Definition and classification of cancer cachexia: an international consensus. Lancet Oncology 201 I; 12:489-95. doi:|0.1016/SI470-2045(I0)70218-7

7 Galbraith S, Fagan P, Perkins $P$ et al. Does the use of a hand held fan improve chronic dyspnoea? A randomized, controlled, crossover trial. J Pain Symptom Manage 2010; 39:831-38. doi:10.1016/j. ipainsymman.2009.09.024

8 Tracey I. Getting the pain you expect: mechanisms of placebo, nocebo and reappraisal effects in humans. Nat Med 20 10; 16:127783. doi: $10.1038 / \mathrm{nm} .2229$ 